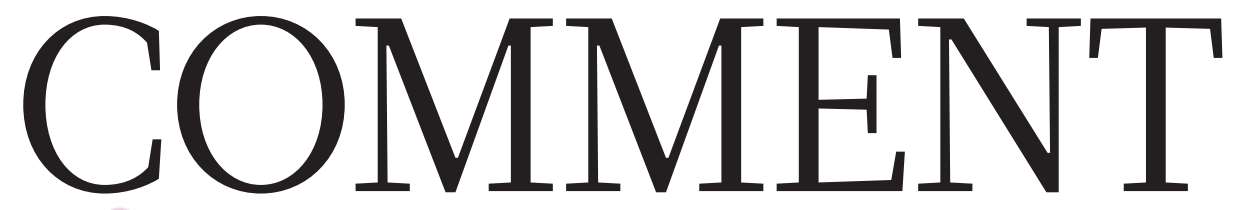

Books Journey through the microbiological jungle within us p.146
EDUCATION Boosting creative teaching in India's schools p.148
DIVERSITY The forgotten women of Antarctic research $\mathbf{p . 1 4 8}$
FUNDING Recognize the reach and needs of interdisciplinary research $\mathbf{p . 1 4 8}$

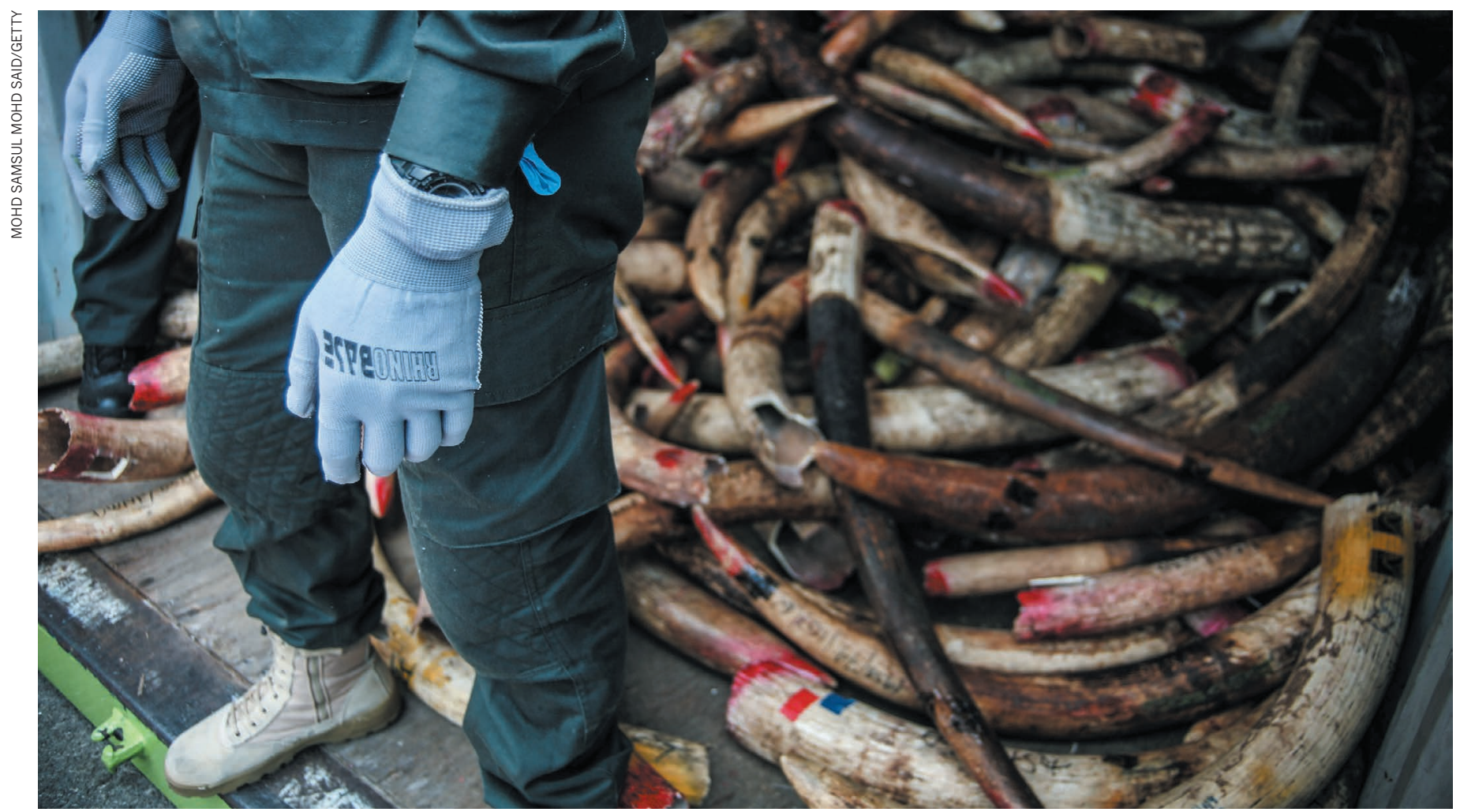

A container of seized African elephant tusks in Malaysia.

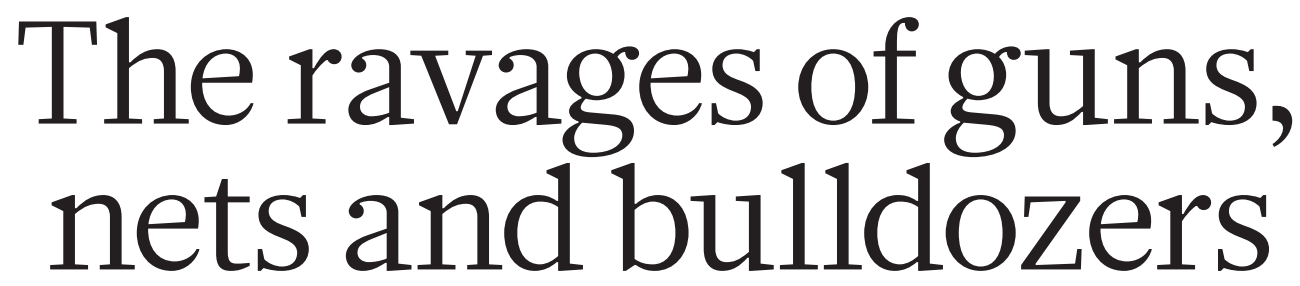

The threats of old are still the dominant drivers of current species loss, indicates an analysis of IUCN Red List data by Sean Maxwell and colleagues.

$\mathrm{T}$ There is a growing tendency for media reports about threats to biodiversity to focus on climate change.

Here we report an analysis of threat information gathered for more than 8,000 species. These data revealed a contrasting picture. We found that by far the biggest drivers of biodiversity decline are overexploitation (the harvesting of species from the wild at rates that cannot be compensated for by reproduction or regrowth) and agriculture (the production of food, fodder, fibre and fuel crops; livestock farming; aquaculture; and the cultivation of trees).

Early next month, representatives from government, industry and non-governmental organizations will define future directions for conservation at the World Conservation Congress of the International Union for Conservation of Nature (IUCN). High on the agenda for political leaders, non-governmental organizations, conservationists and many others will be taking steps to turn the 2015 Paris climate agreement into action. It is also crucial that the World Conservation Congress delegates - and society in general - ensure that efforts to address climate change do not overshadow more immediate priorities for the survival of the world's flora and fauna.

\section{ON THE LIST}

Since 2001, the categories and criteria of the IUCN Red List of Threatened Species - a standard for the evaluation of extinction 


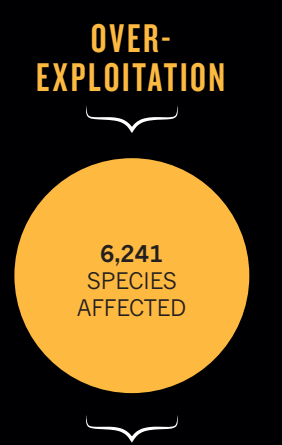

More than $80 \%$ of species analysed are harmed by more than one sub-class threat.

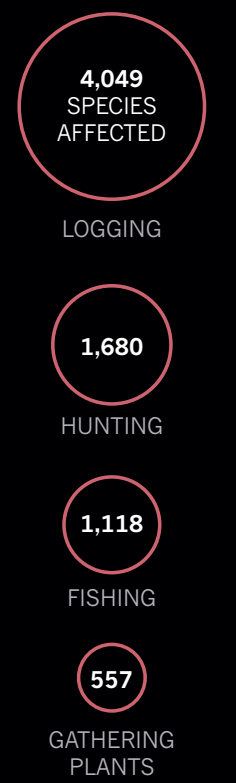

AGRICULTURAL ACTIVITY
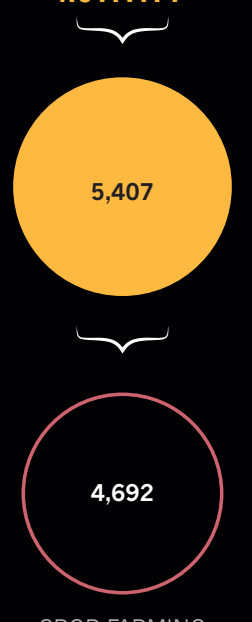

CROP FARMING

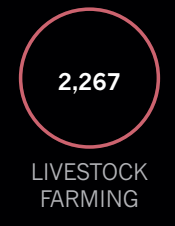

730

TIMBER PLANTATIONS

\section{URBAN \\ DEVELOPMENT}
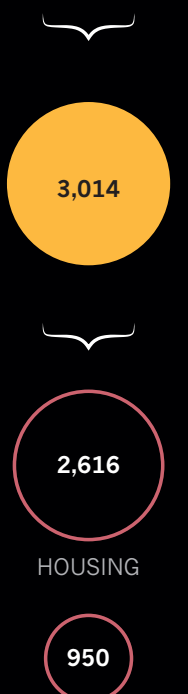

TOURISM AND

RECREATION

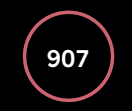

INDUSTRIAL
INVASION
AND DISEASE
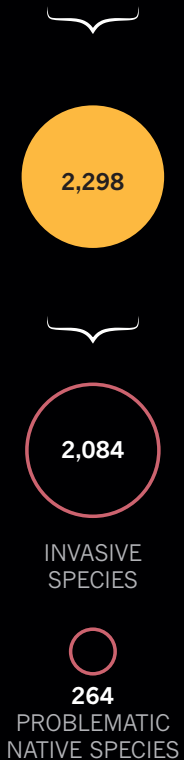

NATIVE SPECIES

14

$\stackrel{14}{\text { INTRODUCED }}$

GENETIC

MATERIAL
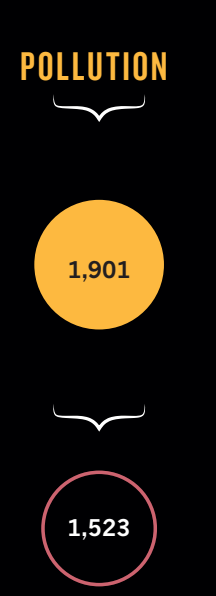

AGRICULTURE

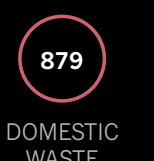

807

INDUSTRIAL

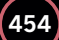

454
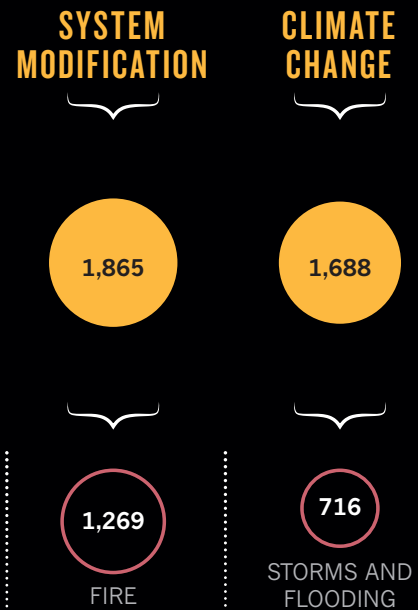

STORMS AND FLOODING

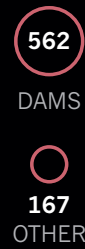

167
OTHER

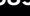

HABITAT MODIFICATION

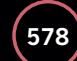

EXTREME TEMPERATURES

(347)

DROUGHT
The Sumatran rhinoceros (Dicerorhinus sumatrensis) and Western gorilla (Gorilla gorilla) are being harmed by overexploitation; Africa's cheetah (Acinonyx jubatus) and Asia's hairy-nosed otter (Lutra sumatrana) are being imperilled by agricultural activity.
> risk - have guided assessments, now for 82,845 species. Assessors assign species to categories, including 'near-threatened', 'vulnerable,' 'endangered' or 'critically endangered' depending on their population size; past, current and projected population trends; geographic range and other symptoms of extinction risk. Species in the latter three groups are collectively referred to as 'threatened'.

To assess the relative prevalence of current hazards to biodiversity, we quantified threat information for 8,688 near-threatened or threatened species belonging to species groups in which all known species have been assessed (for complete list of taxa included, see Supplementary Information; go.nature.com/2ajen88).

The basic message emerging from these data is that whatever the threat category or species group, overexploitation and agriculture have the greatest current impact on biodiversity (see 'Big killers').

Of the species listed as threatened or near-threatened, $72 \%(6,241)$ are being overexploited for commerce, recreation or subsistence.

The Sumatran rhinoceros (Dicerorhinus sumatrensis), Western gorilla (Gorilla gorilla) and Chinese pangolin (Manis pentadactyla, a scaly mammal), for instance, are all illegally hunted as a result of high market demand for their body parts and meat. These are just three of the more than 2,700 species affected by hunting or fishing, or by people collecting live specimens for the pet trade. At the same time, unsustainable logging is contributing to the decline of more than 4,000 forest-dependent species, such as the Bornean wren-babbler (Ptilocichla leucogrammica), India's Nicobar shrew (Crocidura nicobarica), and the Myanmar snub-nosed monkey (Rhinopithecus strykeri).

The expansion and intensification of agricultural activity is imperilling 5,407 species $-62 \%$ of those listed as threatened or near-threatened. Africa's cheetah (Acinonyx jubatus), Asia's hairy-nosed otter (Lutra sumatrana) and South America's huemul deer (Hippocamelus bisulcus) are among more than 2,300 species affected by livestock farming and aquaculture. And the Fresno kangaroo rat (Dipodomys nitratoides) and the African wild dog (Lycaon pictus) are two of more than 4,600 species currently under threat from land modification associated with the production of food, fodder or fuel crops.

Meanwhile, anthropogenic climate change - including increases in storms, flooding, extreme temperatures or drought that exceed background variability, as well as sea-level rise - is currently affecting $19 \%$ of species listed as threatened or near-threatened. Hooded seals (Cystophora cristata) are among the 1,688 species affected. These have dropped in abundance by $90 \%$ in the northeastern Atlantic Arctic over the past few decades 
The Spanish imperial eagle (Aquila adalberti) and giant panda (Ailuropoda melanoleuca) are being harmed by road building.
HUMAN DISTURBANCE
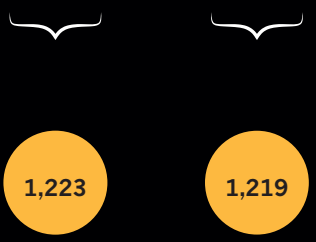

ENERGY
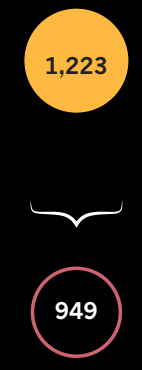

RECREATION

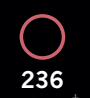

WORK'
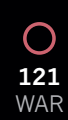
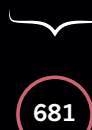

681

ROADS AND

RAILWAYS
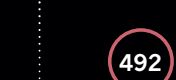

SHIPPING

LANES

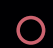

95

SERVICE

LINES AND

INFRASTRUCTURE
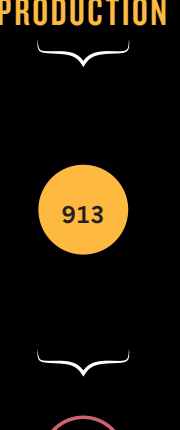

833

MINING

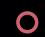

56

OIL AND

GAS

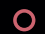

56

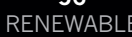

ENERGY

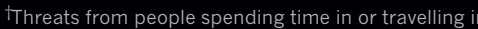

TThreats from people spending time in or travelling i

or military activities.

Major threat classes (orange circles) that harm fewer

than 110 species and sub-class threats (red rings) that

harm fewer than 50 species are not included.

Source: The IUCN Red List of Threatened Species,

Version 2016-1; www.iucnredlist.org

as a result of extensive declines in regional sea ice, and so in the availability of sites for resting and raising pups.

\section{DATA LIMITATIONS}

There are three obvious difficulties in interpreting the Red List data.

First, the patterns we report here do not necessarily extend to taxonomic groups that haven't been monitored. The comprehensively assessed groups included here are not a random sample from the tree of life $e^{1}$, but those that are generally better-studied. All known bird species have been assessed, for instance. But information on extinction risk has been gathered for only some $0.1 \%$ of the more than 50,000 species of fungi thought to exist.

A second potential limitation of our analysis is that it treats threats as discrete when, in fact, hazards rarely affect organisms in isolation. Agriculture is a major driver of greenhouse-gas emissions, for example. And new roads to enable agricultural expansion

can increase bush-meat harvesting, the incidence of forest fires and habitat fragmentation $^{2}$. In fact, more than $80 \%$ of the species included in our analysis are affected by more than one major threat.

Finally, the balance of threats driving extinction risk for many of the world's species will change, even over the next few decades ${ }^{3}$. For Red

List assessments, the

impacts of future threats (including climate change) in reducing a species' population size are projected across three generations or over a ten-year period -

\section{"Climate change will become an increasingly dominant problem in the biodiversity crisis."} whichever is longer. Hence, unless the species being assessed is long-lived (with an expected lifespan of 30-50 years, say), projections cover a period during which the effects of climate change, in particular, will be relatively modest.

Yet we do not think that any of these caveats alter the overall message. Because agricultural activity and overexploitation tend to occur in fertile places with naturally high levels of biodiversity ${ }^{4}$, the patterns emerging from our analysis probably extend to many of the other species that have not yet been assessed. Also, until a better understanding is obtained of how threats act additively, synergistically or antagonistically, a pragmatic course of action is to limit those impacts that are currently harming the most species $^{5}$. Finally, studies have shown Red List categorizations reflecting projected extinction risk from climate change to be more robust than was previously thought ${ }^{6}$.

\section{WHAT NEXT?}

Of all the plant, amphibian, reptile, bird and mammal species that have gone extinct since AD 1500, 75\% were harmed by overexploitation or agricultural activity or both (often in combination with the introduction of invasive alien species ${ }^{7}$ ). Climate change will become an increasingly dominant problem in the biodiversity crisis ${ }^{3}$. But human development and population growth mean that the impacts of overexploitation and agricultural expansion will also increase.

The aim of the World Conservation Congress is to translate sustainable development and carbon neutrality agreements into action. We urge delegates to focus on proposing and funding actions that prioritize the biggest current threats to biodiversity.

Thankfully, there are effective tools and approaches to alleviate harm caused by overexploitation and agricultural activities $^{8}$. These include the development and governance of sustainable harvest regimes; the enforcement of hunting regulations and no-take marine protected areas; the maintenance of international policy mechanisms; such as the Convention on International Trade in Endangered Species; and public education (for instance, on where ivory comes from) to reduce demand. Also powerful are the establishment of protected areas to safeguard key biodiversity areas ${ }^{9}$; the management of agricultural systems in ways that allow threatened species to persist within them; the regulation of pesticide and fertilizer use; the certification of agricultural sustainability; and the reduction of food waste, for example, using urban foodtransfer programmes.

Crucially, ensuring that overexploitation and agricultural activities today do not compromise ecosystems tomorrow will help to ameliorate the challenges presented by impending climate change. Healthy ecosystems are better repositories for carbon. They are also more likely to provide the physical connectivity and genetic diversity needed to enable species to adapt to the large shifts in climate expected later this century ${ }^{10}$.

Conservationists, weary of tackling herculean, long-standing problems, could be forgiven for being drawn to newer ones. Nonetheless, we appeal to all concerned with the sustainability of life on Earth to take stock of the current balance of threats - and refocus their efforts on the enemies of old.

Sean L. Maxwell is a PhD student in the School of Geography, Planning and Environmental Management, University of Queensland, Brisbane, Australia.

Richard A. Fuller is an associate professor in the School of Biological Sciences, University of Queensland, Brisbane, Australia. Thomas M. Brooks is head of science and knowledge at the International Union for Conservation of Nature, Gland, Switzerland. James E. M. Watson is associate professor in the School of Geography, Planning and Environmental Management, University of Queensland, Brisbane, Australia, and director of the Science and Research Initiative at the Global Conservation Program, Wildlife Conservation Society, New York, USA. e-mail:smaxwell@uq.edu.au

1. Brooks, T. M. et al. Sci. Data 3, 160007 (2016).

2. Laurance, W. F., Goosem, M. \& Laurance, S. G. W. Trends Ecol. Evol. 24, 659-669 (2009).

3. Foden, W. B. et al. PLoS ONE 8, e65427 (2013)

4. Anderson, B. J. et al. J. Appl. Ecol. 46, 888-896 (2009).

5. Côté, I. M., Darling, E. S. \& Brown C. J. Proc. R Soc. B 283, 20152592 (2016)

6. Keith, D. A. et al. Conserv. Biol. 28, 810-819 (2014).

7. Bellard, C., Cassey, P. \& Blackburn, T. M. Biol. Lett 12, 20150623 (2016).

8. Hayward, M. W. Biodivers. Conserv. 20, 25632573 (2011)

9. Watson, J. E. M., Dudley, N., Segan, D. B. \& Hockings, M. Nature 515, 67-73 (2014).

10.Martin, T. G. \& Watson, J. E. M. Nature Clim. Change 6, 122-124 (2016). 